\title{
Design and Implementation of the Intelligent Counting System
}

\author{
Zhihong Xiao \\ School of Electronic Engineering, Xi'an Shiyou University, Xi'an, China \\ xzhong@xsyu.edu.cn
}

Keywords: Innovation ability, microcontroller, counting system, sensor

\begin{abstract}
This paper introduces the research situation of undergraduate innovation and entrepreneurship training program "Design of Intelligent counting system ". The circuit and software design of the system are also given. The system is consists of computer, microcontroller, power module, signal measurement module, keyboard circuit, audible and visual alarm module, the display module, the clock module, and the serial interface, etc. It can detect and display the number of items through the sensor and the related statistical data. The experimental results show that the system has a high level of measurement accuracy and an anti-jamming capability. Through the exercise of the project, which is beneficial for training students innovative and practical abilities, students learned how to use their knowledge to solve problems in practice.
\end{abstract}

\section{Introduction}

\subsection{Undergraduate Innovation and Entrepreneurship Training Program}

Undergraduate Innovation and Entrepreneurship Training Program is an important part of the Undergraduate Teaching Quality and Teaching Reform Project by Ministry of Education every year [1]. It is an effective way to promote the reform of teaching models and improve the talent training. The program will be completed by a single student or a team under the guidance of professors. Team members need to found the problem, collect data, research and analysis, get the ways and means to solve the problem finally. When the project is finished, the project team members will complete the report and conduct academic exchanges autonomously. It is aimed to change the concept of talent cultivation of the university, improve the innovative quality, rigorous scientific attitude and team cooperation spirit of students, train reserve talents for the country. [2-6]

\subsection{The information of the project "design of Intelligent counting system"}

With the development of the times and the continuous expansion of modern production scale, in order to ensure the real-time and accuracy of statistical data such as the number of personnel and products, it is necessary to install the automatic detection and counting devices to monitor the entry and exit of personnel and the number of products on production lines in real time, etc. At the same time, it also needs to transfer real-time data to the computer management system to provide basis for security management and process control [7-8].

The system is based on the stc12c5a60s2, the Infrared diffuse reflection photoelectric switch and infrared human sensor are used as the transducer which count the number of items passing through the sensor in real time. The system must have many functions such as detecting and displaying the number of items, displaying the time and other related statistical data, giving an alarm when an exception occurs, setting parameter online, communicating with the computer to upload detection data, etc. The intelligent counting system can be widely used to record the quantity of production products in real time on the assembly line, and distinguish the entry and exit of people in mines, warehouses, dormitories, and other places. 


\section{The composition of the system}

The system is consists of computer, microcontroller, power module, signal measurement module, keyboard circuit, audible and visual alarm module, the display module, the clock module, and communication circuit. etc. System diagram is shown in Figure1.

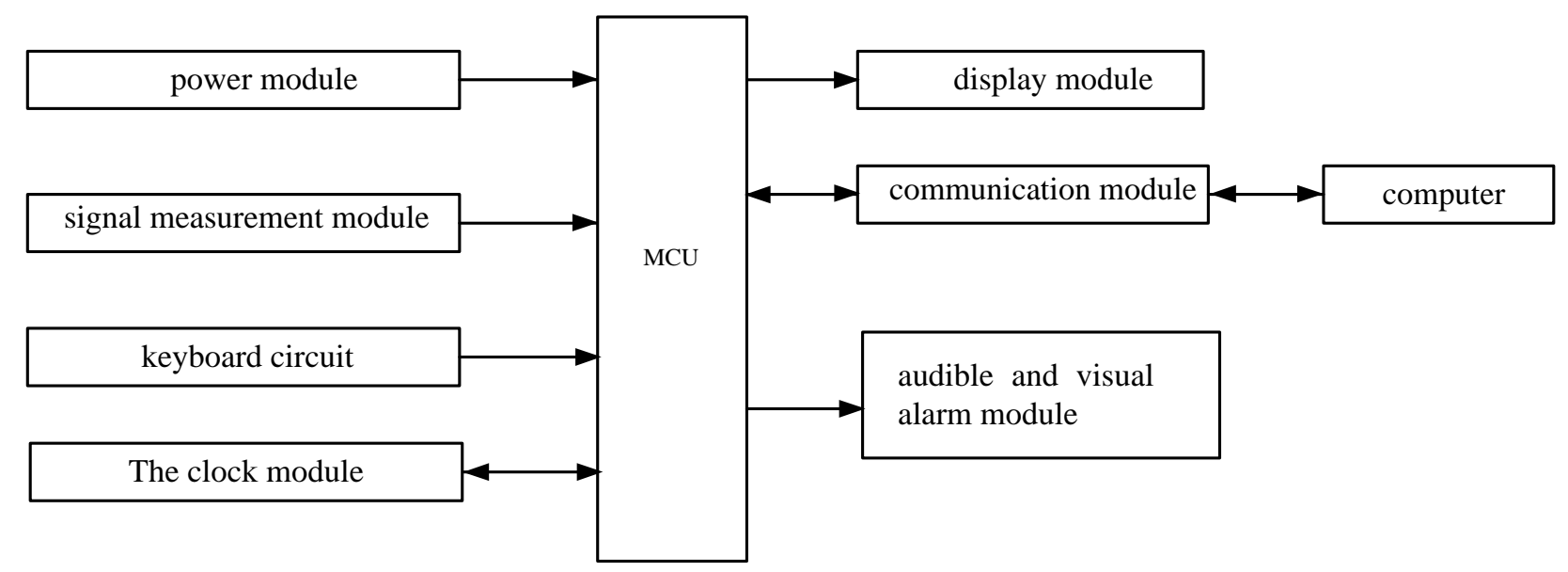

Figure 1 The hardware block diagram of the system

The stc12c5a60s2 is a high-performance CMOS 8-bit microcontroller with 8KB FPEROM-flash programmable and erasable read only memory, it uses the classic MCS-51 kernel, and a lot of improvements have been made to make the chip have the features that traditional 51 microcontroller do not have. The device is compatible with the industry-standard 80C51 instruction set and pinout.

The system clock uses $12 \mathrm{MHz}$, port 0 is data port, P1.0 P1.1 are connected to the alarm circuit, P1.2 P1.6 are connected to the keyboard circuit, port 2 is used to address control, P3.2 P3.5 are connected to the signal measurement circuit.

\subsection{The keyboard circuit}

The keyboard circuit's function is to determine working parameters, the contents of the display and the working state of the system. There are two kinds of working state of the system, such as setting state and running state, Among them, the setting state is used to set and correct the working parameters and current time. The keyboard circuit consists of 5 keys, which are set button, left shift button, right shift button, plus one button, minus one button.

\subsection{Signal measurement module}

The signal measurement module is a very important part of the system. It is used to measure the number of targets passing through the sensor. The measurement sensor uses E3F-DS30C4, which is an infrared diffuse reflection photoelectric switch with an action display indicator. Its detection distance is adjustable; Operating voltage is DC6V-30V.

The signal measurement circuit is shown in Figure2. N1 and N2 are E3F-DS30C4, and their output signals are valid at low levels. When the target to be measured passes, the effective signal is filtered and transformed and sent to the microcontroller for counting. The circuit can realize the discrimination function. When the target is passing in a positive direction, the counter value adds 1 . When the target passes in reverse, the counter value subtracts 1 . In order to distinguish whether the measurement target is a person or an object, there is an auxiliary measurement sensor, in addition to measuring sensors $\mathrm{N} 1$ and N2, when a human body passing through, auxiliary measurement sensor produces an effective signal and is processed and sent to a microcontroller. The auxiliary measurement sensor uses the HC-SR 501, which is a human infrared induction electronic module sensor. It uses the German imported LHI 778 probe based on infrared technology to detect the 
infrared rays emitted by the human body. Its sensitivity is high and its reliability is strong, with ultra-low voltage operating mode, the operating voltage is DC $4.5 \mathrm{~V}-20 \mathrm{~V}$.

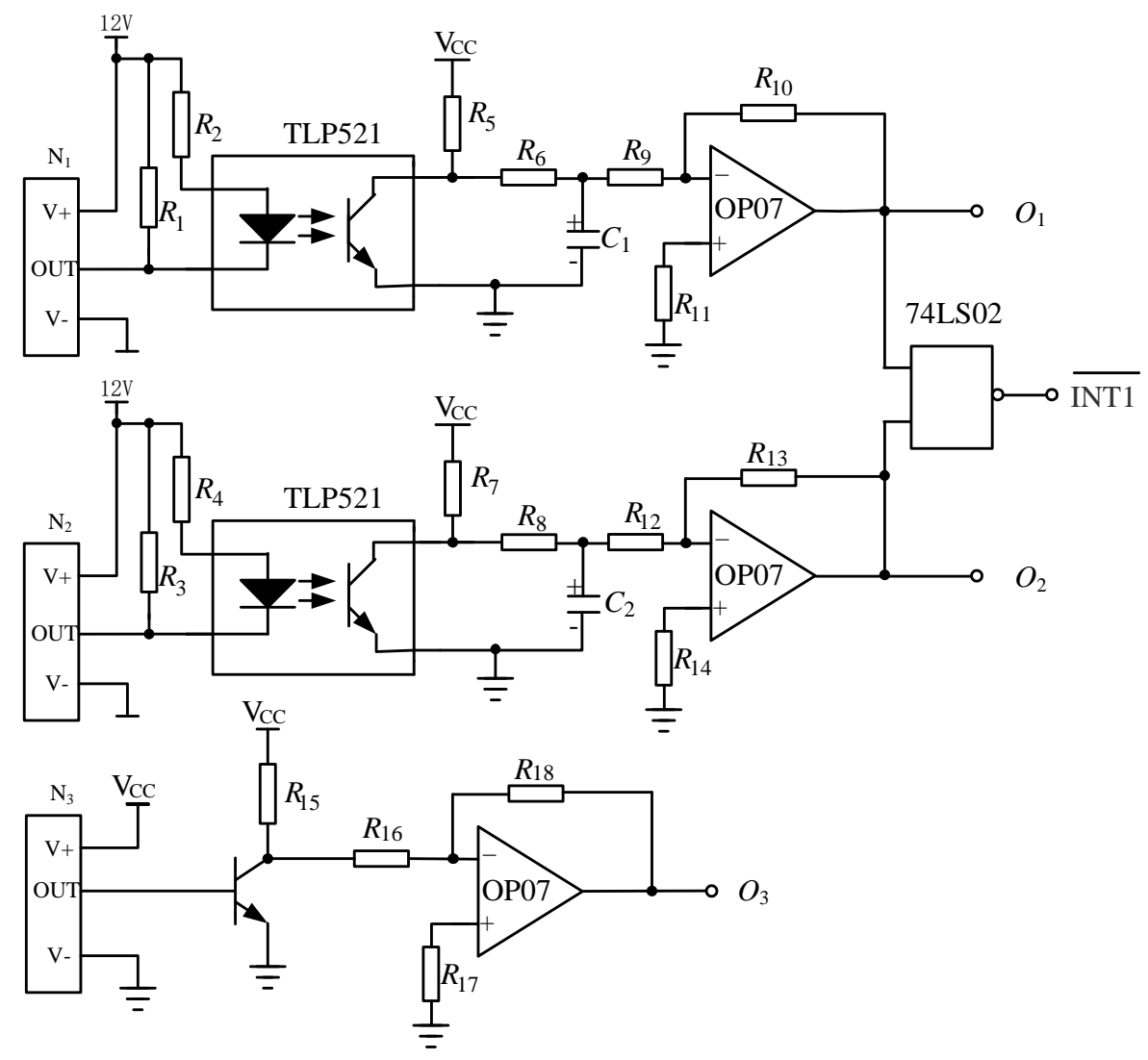

Figure2 Signal measurement circuit

\section{The system software}

The system software is designed modularly and consists of main program, interrupt subroutine, LCD showing subroutine, serial Communication subroutine, key processing subprogram, etc. The main program completes the initialization of the device and calls the appropriate subroutine modules according to the system requirements. The main program block diagram is shown in Figure3.

\section{Conclusion}

After debugged, the system was tested for performance, The test results show that all aspects of the system meet the requirements. The correct rate of counting has reached $100 \%$. Figure 4 is the system debugging picture. The test record table used to measure the number of products on a production line is shown in table 1.

Table 1 test record table

\begin{tabular}{|c|c|c|c|}
\hline \multirow{2}{*}{$\begin{array}{c}\text { The } \\
\text { number }\end{array}$} & \multicolumn{2}{|c|}{ Actual values } & \multirow{2}{*}{ Measured values } \\
\cline { 2 - 3 } & Number of people & number of objects & 0020 \\
\hline 1 & 0 & 20 & 0100 \\
\hline 2 & 3 & 100 & 0200 \\
\hline 3 & 5 & 200 & 0300 \\
\hline 4 & 6 & 300 & 0500 \\
\hline 5 & 6 & 500 & 1000 \\
\hline 6 & 7 & 1000 & \\
\hline
\end{tabular}




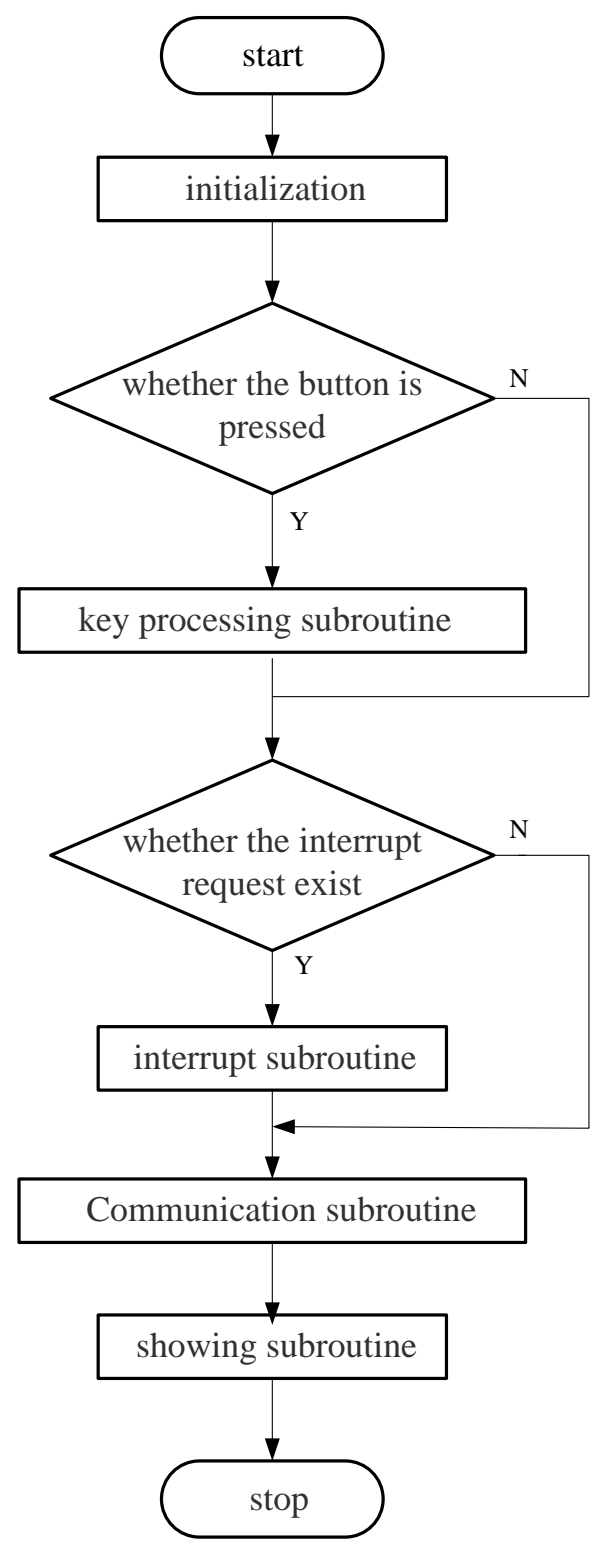

Figure 3 The main program block diagram

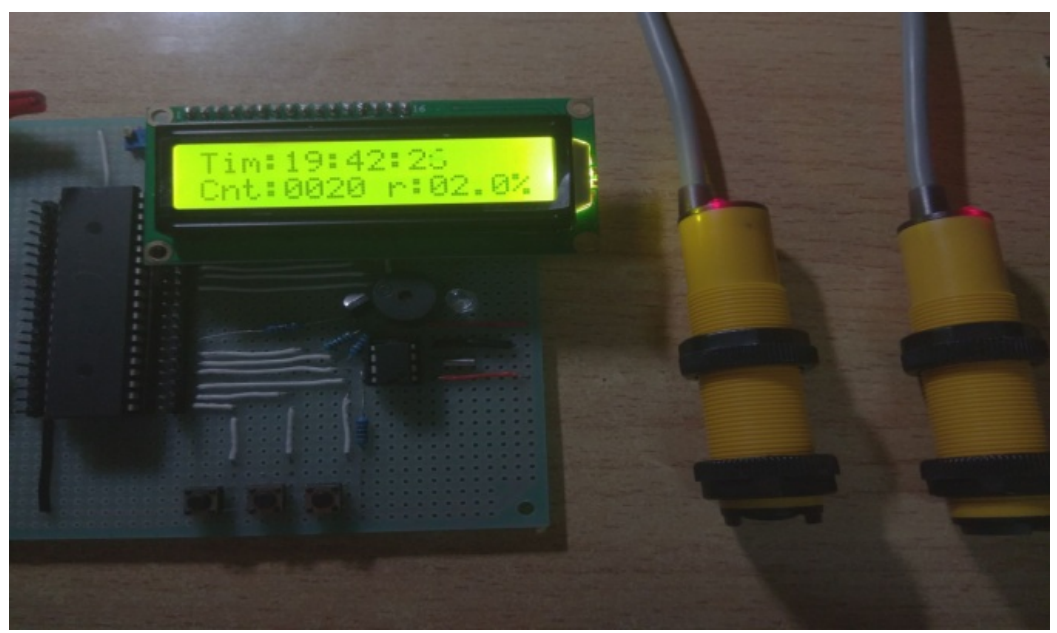

Figure 4 System debugging picture 


\section{Acknowledgements}

The author would like to express her gratitude to the help to the Undergraduate Innovation and Entrepreneurship Training Program Established by the Ministry of Education. Thanks are also to Xi'an Shiyou University and all colleagues who previously provide support.

\section{References}

[1] Information on http://www.moe.gov.cn/publicfiles/business/htmlfiles/moe/s5972/201404/xxgk _166881.html.

[2] LIU Chang-hong, LI Xiao-hui, LI Gang, YUE Qing-rong, Ren Yong-gong. (2014)Practice and Exploration of the Undergraduate Innovation and Entrepreneurship Training Program. RESEARCH AND EXPLORATION IN LABORATORY,5,163-166.

[3] ZOU Yu-tang, ZHANG Hong, XU Rui-xue, SHI Miao. (2012)A Tentative Study on Training Mechanism Based on the Undergraduate Innovationand Entrepreneurship Education Base.Education Teaching Forum, 2, 39-40.

[4] WU Zhiwei, LIU Xin, CHEN Qi, LIU Zhiyong, LIU Guoguang, CHENG Guoyong. (2015)Application of pavement detection methods based on buried sensor on training programs of innovation and entrepreneurship for undergraduates. Journal of Architectural Education in Institutions of Higher Learning, 24, 116-119.

[5] Lu Ling Wang Li. (2017)Problems and Suggestions on Implementation of Undergraduate Training Program for Innovation and Entrepreneurship. 2017 International Conference on Economic Development and Education Management (ICEDEM2017), 252-255.

[6] XIE Yunjiang, ZHAO Cong. (2016) Process Management of Undergraduate students' Innovation and Entrepreneurship Trainning Programs. China Education of Light Industry, 3, 29-30.

[7] Pornpanomchai, Chomtip,Stheitsthienchai, Fuangchat, Rattanachuen and Sorawat, (2012) Object detection and counting system.1st International Congress on Image and Signal Processing, (CISP 2012) ,2, 61-65.

[8] Tang YU, (2017) Design of Multifunctional Table Tennis Billiards Counter Based on Single Chip Computer. Digital Technology and Applications, 9, 5-6. 